\title{
Noche amable más que la alborada. Resto irreductible, fatalidad metafísica y superación del mal en F. W. J. Schelling
}

\author{
A propósito de Ana CARRAsco-Conde, La limpidez del mal. \\ El mal y la historia en la filosofía de F. W. J. Schelling, \\ Madrid, Plaza y Valdés, 2013, 289 pp. \\ Nuria SÁNCHEZ MADRID \\ Universidad Complutense de Madrid \\ nuriasma@filos.ucm.es
}

Es una evidencia que la historia del pensamiento no ha hecho justicia a la odisea de la conciencia articulada y desplegada por F. W. J. Schelling, lo que permite valorar con mayor admiración si cabe la escondida y solitaria senda por la que se adentran quienes se reconocen como especialistas en su obra, lejos de un mundanal ruido al que siempre resultó más simpático el organicismo aristotélico renovado desde el denuedo del concepto. La reivindicación se verá aún más legitimada si se atiende a la sólida contribución llevada a cabo por este autor para evitar toda aproximación abstracta al proceder dialéctico, trayendo a superficie los obstáculos que el querer del sujeto impone a toda presunta transparencia teleológica. Si la poética del telos subsiste en Schelling, como así creemos, lo hará formando una elipse sostenida sobre un doble foco, uno visible y otro fuera de campo, pero ambos igualmente constituyentes y decisivos con respecto al examen de lo real. Será menester así referirse a una teleología que cuando presume progresar, retrocede, y que avanza en la medida en que se enfrenta a un abismo que ejerce la función de límite extremo de la deliberación y explicación. Con su tozuda insistencia, este complejo progreso confirma que hay fines que se alcanzan con mayor determinación en la medida en que el sujeto se aparta de ellos o, mejor dicho, en que se libera de la influencia de un ídolo que enmascaraba lo que hasta entonces se había apreciado como ideal.

No es de hecho inhabitual que la discusión académica actual a propósito del Idealismo alemán cuestione la consistencia racional de la dialéctica del de Leonberg, apelando a una miope disciplina categorial kantiana o empleando una metaforología de inequívoco origen hegeliano, que prioriza la presunta operatividad del organismo, manteniendo en reserva sus puntos ciegos e impidiendo así que la(s) clave(s) de la arquitectónica del sistema schellinguiano se visibilicen en total autonomía con respecto a otros planteamientos y perspectivas más unilaterales y menos genetis- 
tas. Que el acceso a esta obra haya permanecido generalmente supeditado al previo desmontaje de los reproches de oscurantismo, vaguedad conceptual, coqueteo con la teología y conservadurismo político no es sino un fenómeno sintomático de las espurias exigencias que a menudo rigen la práctica de la historiografía filosófica. En efecto, tales condiciones han venido operando como anteojos que impiden contemplar el esfuerzo impenitente de Schelling por averiguar qué esconde y por medio de qué complejos procesos se ha ido configurando la conciencia, ese inquietante producto, un ente que sólo la potente retórica cartesiana pudo considerar como un dato originario. De alguna manera, Schelling nos enseña que lo más propio es siempre lo más siniestro. Esta nota sentimental es sumamente elocuente, y es menester localizar su causa inmediata en el paisaje lunar de una gramática ontológica que poco tiene de platónica y solar. Una gramática en la que, por el contrario, un "resto irreductible" (Carrasco-Conde, p. 251) ${ }^{1}$ ocupa el lugar del rey. De este nuevo mapa ontológico se sigue la enseñanza que transmite que el ser humano nunca vence sin haber caído antes, y que la victoria no es sino la superación de una perversión originaria - una inversión de los principios y dislocación de la unidad - que nunca podrá deshacerse de aquel inquietante contrincante, por mucho que esté en situación de verlo convertido en una realidad potencial. La metafísica del mal introduce de esta manera una nueva perspectiva en la pregunta por el ser (p. 229). Este es el ambicioso alcance, espléndidamente desplegado, de la monografía que nos ocupará en estas páginas. Es mérito de la profesora de la Universidad Complutense de Madrid, Ana Carrasco-Conde, prestigiosa especialista en el Idealismo alemán, el haber ofrecido al público interesado del ámbito hispanohablante valiosos ensayos - algunos en trance de ser publicados - que arrojan una luz insólita sobre la concepción de la razón, de la conciencia y de su tensa dialéctica interna en Schelling, poniendo asimismo de manifiesto la radical actualidad de la reflexión que este autor propone sobre el mal y la opacidad que la conciencia padece con respecto a su páthos originario. El trabajo entronca con una línea interpretativa en lengua castellana emparentada con exposiciones previas de Arturo Leyte y Vicente Serrano, indiscutiblemente preciosas para quien pretenda sumergirse en las profundidades del absoluto schellinguiano.

Partiremos señalando la opacidad estructural de la conciencia, pues no en vano nos enfrentamos a un pensamiento para el que "el espíritu huye de sí mismo mientras se busca" 2 (Carrasco-Conde, p. 24). La historia está atravesada por esa misma dificultad para advertir qué fuerzas o potencias están actuando como su genuino motor. Probablemente, ese impulso resida justamente en lo que más se encubre y rechaza, a saber, el mal. Por ello, difícilmente podrá pronunciarse el lector acerca del ensayo $L a$ limpidez del mal sin hacerse cargo de la asombrosa capacidad de quien lo firma para proyectar luz sobre los estratos más recónditos del yo y levantar acta de la perversión

\footnotetext{
${ }^{1}$ F. W. J. Schelling, Sämtliche Werke (=SW), Stuttgart, Cotta, 1856-1861. Vd. SW I/7, p. 360.

${ }^{2} \mathrm{SW} \mathrm{I} / 3$, p. 628.
} 
primera de cuya mano el ser humano se va haciendo con un espacio propio, a saber, con la posesión gravosa de su propia mismidad [Eigenheit], en una epopeya itinerante de la conciencia que resulta, por qué callarlo, bastante más implacable con su propio fondo oscuro y con la sangre que rebosa del cáliz de los espíritus (p. 27) que la relatada por Hegel. El paradigma de la superación [Überwindung] resulta sin lugar a dudas bastante más fructífero que el de la supresión [Aufhebung] cuando se pretende abordar la historicidad del absoluto, toda vez que la segunda se muestra más interesada en alcanzar eficazmente el resultado anhelado que en delimitar sin distorsiones teleológicas la inversión que se gestó al principio - el Urtatsache der Geschichte, en palabras de H. Fuhrmanns - y ya nunca dejará de acompañar insidiosamente a todo lo que es. Frente a las poéticas heroicas de la conciencia y la historia, en las que siempre se asigna un papel secundario al mal introducido por la mano humana, Schelling anima a entender la deriva del mal como precipitado de una curvatura del yo sobre sí mismo que origina el orden del apetecer e introduce en el mundo, esto es, pone en la existencia la realidad de la inversión, el desorden y la fragmentación. Así, pues, el yo decae en su pertenencia a la unidad primigenia con la Naturaleza y Dios desde el momento en que pretende ser sí mismo, pero al mismo tiempo, ese querer le permite alcanzar conciencia de lo que ha perdido y de la rehabilitación que puede operar en su persona. La conciencia de la sanación, que como en los cuartetos de cuerda tardíos de Beethoven recupera algo parecido a la felicidad de la mano de la contemplación de paisajes baldíos, en los que el mal se manifiesta en su extrema limpidez, como "la eterna latencia y la negatividad del sistema" (p. 279). Emprendamos la marcha al ritmo del triple movimiento con que Carrasco-Conde expone los momentos — posibilidad, efectividad y necesidad — que articulan la realidad del mal en Schelling.

Otra de las virtudes a destacar del ensayo de la profesora Carrasco-Conde consiste en su respetuosa puntualización de la especificidad del pensamiento de Schelling de la mano del uso peculiar que este realiza de términos como conciencia, yo o historia. Si partimos de la capacidad del yo para abismarse en los estratos de su interioridad, resulta evidente - sostiene la autora del ensayo - que la actividad del sujeto para volverse sobre sí mismo no representa en Schelling lo mismo que en Fichte, desde el momento que ese movimiento está dirigido en el primero por un querer que está más próximo de una oscura ansia [Sehnsucht] que de una representación de la relación presuntamente transparente que el sujeto mantendría consigo mismo. El ser originario - como Ungrund o Urgrund, como comienza a llamársele a partir del Freiheitsschrift de 1809- no aclara, sino que más bien encubre, convirtiendo al sujeto en un producto de sí mismo, cuyas leyes de constitución resultan imposibles de efabilizar. En este contexto, el problema del mal no puede encontrar una explicación siquiera plausible sin atender a "una necesidad ontológica de carácter fundante" (p. 264) o a un "aguijón innato al alma" (p. 44) en la terminología más platónica del escrito de Schelling Filosofía y religión, a saber, sin mirar de frente al combate que 
la fuerza expansiva intrínseca a todo lo existente mantiene con la fuerza contractiva del fundamento. Sin embargo, ningún ente combatirá con el último principio con la virulencia y consecuencias que pone en juego el ser humano, de cuya decisión brotan ambas fuerzas, entreveradas en los misterios de un querer persistente, pero desprovisto de ideal teleológico.

Sería un error considerar al Ungrund un plagio de obra de Böhme, en la línea de las acusaciones vertidas por Eschenmayer (p. 69), de la misma manera que sobredimensionar el ascendiente del neoplatonismo en Schelling, que recupera tales conceptos relegados al trastero metafísico para dotarlos de una fuerza inusitada hasta el momento. Por de pronto, el Ungrund se entiende como una frontera insuperable para el mapa dibujado por la ontología, a saber, como un obstáculo para la voluntad de dar razón, en tanto que lo sumamente contraído y clausurado en sí mismo (p. 70). Hablamos de una suerte de cháos o abismo originario, al modo del ideado por la teogonía hesiódica, que sólo produce el mundo como resultado colateral de su voluntad de expresarse a sí mismo. Se trata de un absoluta indiferencia que invita a nombrar el génesis con la segunda letra del abecedario, con la letra bet, como señala Luigi Pareyson en su Ontología della libertà y recuerda oportunamente Carrasco-Conde (p. 73). He aquí una de las preocupaciones más constantes del pensamiento de Schelling desde la Naturphilosophie pasando por la filosofía de la identidad, a saber, la exteriorización del absoluto o el paso de lo infinito a lo finito. Todo lo que hay se encuentra sosteniéndose frente a - Gegen-wart - un pasado que permanece indomeñable, en tanto que fondo inaprehensible. Schelling preconiza que la historia del ser sólo estará completa cuando se advierta la radical dependencia que todo lo existente mantiene con un fundamento indisoluble, que despliega y genera la diferencia sin renunciar a una latencia perpetua, como una Naturaleza anceps, enigmática y origen de todo lo que hay (p. 82). La acusación hegeliana de que con ello se inaugura el "sistema del columpio" o la acusación de la semejanza del Grund con una "palanca" por parte de Eschenmayer deberán demostrar a este respecto que cabe un fundamento más profundo que esa contraposición de gravedad y luz, en la que hay poco de mecánico y mucho de proceso vital o, si se prefiere, que su superación por obra del concepto no es únicamente una figura discursiva más, incapaz de silenciar el poderoso latido que subyace a lo que existe ${ }^{3}$.

El conflicto de fuerzas que la Naturaleza alberga, a la que debe tomarse por un auténtico ser vivo, aparece como manifestación del propio deseo de serse (p. 95) de la divinidad, siempre tendente a la manifestación (p. 116), lo que se conforma a la vez como un apetito ciego que acompaña a cada ente desde su nacimiento, y que aleja a la filosofía natural de Schelling de modelos tan diferentes entre sí como el de Newton o el de Spinoza. Carrasco-Conde apela en este punto a la figura de von Baader, así como a la voluntad de la cólera y la voluntad del amor de Jakob Böhme, citados literalmente al

\footnotetext{
${ }^{3} \mathrm{SW} \mathrm{I} / 8$, p. 177.
} 
final del Freiheitsschrift, como precedentes cruciales para la comprensión del contexto de esta tesis. Todo en la naturaleza consiste en procesos y expresiones de las fuerzas de contracción y expansión que configuran realidad, un enfoque cercano al adoptado por Kant en la Crítica del Juicio teleológico — véanse los $\S \S 80$ y 85 a modo de ejemploy en los principios de la dinámica expuestos en Principios metafisicos de la ciencia de la naturaleza. A este respecto las consideraciones sobre el movimiento de curvatura que comporta el gebähren de cada ente resultan especialmente esclarecedoras (p. 91). La dependencia de las cosas en su devenir y en su despliegue [Entfaltung] desde un fundamento no se solapa con una dependencia con respecto a su ser: si los entes están separados de Dios, no puede decirse que permanezcan separados de él (p. 103), pues se clasifican tomando como referencia el corazón sin temblor de la rotunda verdad, a saber, la unidad previa a la escisión de fuerzas. Por esa cercanía con respecto del fundamento, la voluntad propia [Eigenwille] de la criatura resulta inaccesible para las razones del entendimiento ${ }^{4}$. En el mapa de sucesivas expansiones y contracciones, sin descartar el equilibrio entre potencias, con que se va configurando la Naturaleza - se remite en el ensayo al esclarecedor esquema propuesto por Heuser-Keßler-, en el hombre "se encuentra todo el poder del principio oscuro y a la vez toda la fuerza de la luz" (p. 106), como confirma la emergencia del espíritu. Su existencia transcurre en la encrucijada entre la experiencia del abismo y la conciencia de la superioridad del cielo. El devenir de la naturaleza refleja así la historia de Dios, sin verse forzada a aceptar su superación en beneficio del espíritu.

Pero la centralidad cosmológica del ser humano, entre el cielo y el abismo, tiene corta duración, habida cuenta de que su libertad se manifiesta no sólo como autonomía, sino especialmente desde su capacidad de subvertir el orden, al pretender que su propia voluntad actúe como voluntad central [Zentralwille] del universo (p. 119). Con esta dislocación se confirma lo que de promesa de de-creatio había en la creación del ser humano, que encuentra su perfecta expresión en la mezcla de nada y de esencia real que es el mals. No habrá curación de tal alteración que no pase por restablecer la relación de la periferia con el centro, esto es, por disolver la conexión entre el germen de la dolencia y el punctum vitae del enfermo, siguiendo las doctrinas de J. B. Helmont. El ser nacido libre produce por generatio aequivoca un no-ente que lo parasita, por obra de su propia irritabilidad interna derivada de aquella alteración de las posiciones y de los principios, lo que denota el ascendiente de las teorías de Brown y de Röschlaub en Schelling. La generación de ese no-ente facilita entender que el mal — das Böse, emparentado con aufblasen o hinchar- posee en la lengua alemana el matiz de la hinchazón de la luz espiritual que el sujeto debía por el contrario difundir (pp. 126-127). El mal no debe confundirse, pues, con mera inercia, limitación o privación, al modo de la Teodicea de Leibniz, sino más bien como una consecuencia del orden vital doble que rige

\footnotetext{
${ }^{4} \mathrm{SW} \mathrm{I} / 7$, p. 363.

${ }^{5} \mathrm{SW} \mathrm{I} / 7$, p. 459.
} 
la Naturaleza toda, esto es, como un efecto de la profundidad metafísica - más que moral o ética - que caracteriza al principio del mal y del bien. La "solicitación al mal" (p. 133) que siente el ser humano se ve agudizada por el movimiento reflexivo sobre sí del sujeto que comporta ilusiones como el Selbstsucht, generadas por esta curvatio de la mismidad sobre sí, que procede por analogía con la egoidad divina, pura contracción constituyente del fondo de toda existencia, de la que nos hablan las Lecciones privadas de Stuttgart ${ }^{6}$. Pero la tendencia egocentrista del ser humano rompe con el equilibrio de fuerzas natural, disloca todo lo creado y, sobre todo, libera al ello — siguiendo la comparación sugerida por Odo Marquard- que la divinidad bloqueaba y dominaba, como un auténtico katéchon, abriendo la espiral de un ansia tan ciega como ilimitada. El mal "no es más que el fundamento originario de la existencia" [der Urgrund zur Existenz $]^{7}$ (Carrasco-Conde, pp. 141-142).

Tras haber señalado la conexión entre la apertura y simultáneo encerramiento de la mismidad en sí, el ensayo prosigue desentrañando las consecuencias de la encarnación de la filosofía de la naturaleza schellinguiana en una filosofía de la historia, hija de la conciencia y de su original caída, en la que Sandkühler ha visto con lucidez el eje vertebrador de esta teoría de la libertad (p. 207). En efecto, el querer originario del ser humano, cuyos misteriosos designios permanecen encubiertos para él mismo, obliga a superar a Fichte y su "me encuentro queriendo" y, así, a abordar directamente la actividad del yo como una actividad no eminentemente intelectual, sino desiderativa. Ese querer primigenio y persistente, continuamente inquietante para la estabilidad de la conciencia, localiza lo más incomprensible, a saber, la perversión, el desorden y el mal, si bien no suministra patrones racionales para volver estos fenómenos comprensibles. El camino propuesto es bastante distinto. Se busca sostener la mirada ante lo más siniestro y observar esa oscuridad como algo propio, como la cara oscura del sujeto. Esta transformación de las coordenadas de comprensión del sujeto no pueden sino modificar la concepción de la causalidad que aquel pone en el mundo, que Schelling no acepta seguir yuxtaponiendo à la Kant como los respectos escindidos de lo fenoménico y lo nouménico, al considerar necesario referir mutuamente (p. 159) ambas dimensiones, unidas en lo que aparece justamente como el positivo An-Sich de las cosas 9 . Así pues, el sujeto es capaz de descender hasta el fundamento insondable de su carácter, en el que cabe identificar el sentimiento "de no haber llegado a ser [...] solo en el tiempo" ${ }^{10}$ y la certeza de haberse autodeterminado siempre ya de manera extratemporal. Kant había sostenido en el Religionsschrift que el fundamento de la adopción de las máximas permanece oculto al sujeto, si bien el

\footnotetext{
${ }^{6} \mathrm{SW} \mathrm{I} / 7$, pp. 438-440.

${ }^{7} \mathrm{SW} \mathrm{I} / 7$, p. 387.

${ }^{8}$ J. G. Fichte, Fichte Werke (=FW), Berlin/New York, W. De Gruyter, 1971. Vd. FW IV, pp. 19-20.

${ }^{9} \mathrm{SW} \mathrm{I} / 7$, p. 388.

${ }^{10} \mathrm{SW} \mathrm{I} / 7$, p. 386.
} 
examen de una conducta puede permitir conjeturar que está sostenida sobre máximas malas $^{11}$. Pero Schelling va más allá, al hacer del inconsciente la base sobre la que el yo se asienta y comienza a desplegarse.

De la misma manera en que a la historia le precede una protohistoria, la conciencia se muestra, en palabras de Žižek como "un pasado que, a pesar de que nunca ha existido, persiste como la duradera base del presente"12. No importa su realidad en tanto que acontecimiento, sino su función en tanto que condición. Sin lo inconsciente no se completará la figura dialéctica de la conciencia, una posición con la que Schelling se separa igualmente tanto de Kant como de Fichte y Hegel. Puesto que el ser humano no puede sostenerse ad infinitum sobre la cuerda floja de la indeterminación e indecisión, sino que busca definirse, como el mismo Dios y la entera Naturaleza, esto es, como exige el proceso de Revelación, debe decidirse y determinarse generando una escisión contra algo previo, aunque esa anterioridad sea un mero atrezzo mental. Basta con que resulte creíble para la conciencia. Antes de que la elección pueda abrirse paso, debe establecerse el campo de la de-cisión [Ent-scheidung], esto es, el ámbito en que el Urmensch corta con algo y resuelve abrir una senda práctica de la que se concibe como único dueño. Sin ese movimiento no habría caída, esto es, escisión entre los designios de la voluntad universal y los de la voluntad particular del individuo, toda vez que el sujeto quiere serse separándose lo más claramente posible de la figura del Ebenbild de Dios. Ese sería el peccatum originans y el Urtatsache de la historia en palabras de Fuhrmanns. Con anterioridad a ese paso no habría alternativas reales, sino sendas dependientes de la voluntad divina. Por ello, la elección siempre es derivada y dependiente de la escisión originaria que define lo inteligible de la existencia humana. Tal régimen de sentido introduce en el ser humano un cierto modo de encontrarse ambivalente, a saber, el sentimiento "de haber sido lo que es desde toda la eternidad y de no haber llegado a serlo solo en el tiempo" (Carrasco-Conde, p. 174) ${ }^{13}$. Hasta aquí se percibe una pesada carga difícil de sobrellevar para la condición humana, pero al mismo tiempo se eleva orgullosa la perspectiva de la redención, no aquella dependiente de la poética heroica, tendente a hacer del enemigo un ens alienum externo, sino una consciente de las profundas caceras que la melancolía ha abierto en el ser.

A la luz de lo anterior la historia de lo acontecido o Geschichte no puede sino constituir la historia de una catástrofe, como en la sátira de Tieck El mundo al revés, en la que el fondo de la historia supura a través de las heridas abiertas por el tiempo. El phueîn debe entenderse, pues, como explosión del no-ser, como progreso de la de-

\footnotetext{
11 I. Kant, Gesammelte Schriften. Ediciones: tomos 1-22, Berlín, Preussische Akademie der Wissenschaften; tomo 23: Berlín, Deutsche Akademie der Wissenschaften; desde el tomo 24: Göttingen, Berlin, Akademie der Wissenschaften, 1900-. Vd. RGV, AA 06: 21.

${ }^{12}$ S. Žižek, The indivisible remainder. On Schelling and Related Matters, London/New York, 2006, p. 245.

${ }^{13} \mathrm{SW} \mathrm{I} / 7$, p. 386.
} 
creatio y captación melancólica de la realidad de la inversión ${ }^{14}$, no únicamente como un avance de lo que es cargado de una valencia unilateral. Dada la tensión de fuerzas que atraviesa todo lo dado, lo natural es siempre ambivalente y tal ambivalencia se transfigura en el ser humano en conciencia y vida subjetiva. Ambas, Naturaleza y alma humana comparten una Schwermut de la que es difícil recuperarse y que resulta de una transgresión común. La disparidad de posiciones entre Schelling, por un lado, y Kant, Fichte o Hegel, por otro, parte claramente del estrato en que se posicionan a su juicio los modos de encontrarse, ante la realidad del mundo, ante uno mismo y ante lo que se denomina pasado y futuro. De hecho, la esperanza a la que Kant nunca quiso renunciar, sino más bien conceder siempre ventaja en la balanza del ánimo, de la misma manera que el orgullo del Yo fichteano o la satisfacción aparente de la $\mathrm{Au}$ fhebung hegeliana son demasiado positivas o demasiado unilaterales para dar cuenta de la pasión mixta de la atra bilis schellinguiana.

Esta mirada lúcida reconocerá en el mundo la presencia de la ruina, la contemplará como "un paisaje geognóstico" (p. 186) el verdadero bajo continuo de toda symploké dialéctica, a la que subyace una esencial melancolía. Ese será el "hecho interno", como sostiene Schelling en Presentación del empirismo filosófico (p. 830) de la Naturaleza, su más insistente ritmo, anterior y más potente que las formas del concepto. "El tiempo y la historia constituyen así el proceso de despliegue del mal", afirma Carrasco-Conde (p. 183). La perspicacia schellinguiana, que tanto suele disgustar a algunos por contrariar su concepción del ejercicio de la filosofía, hace en este sentido de la búsqueda de una unidad civil en el Estado el eco de una conducta melancólica, disconforme con el haber perdido la cercanía a la divinidad ${ }^{15}$. La unidad del Estado no ofrece más que una unidad artificial que no conformará nunca una verdadera reunión, orgánica como el vínculo que une a Dios con los hombres (pp. 190 y 193; sobre el problema del Estado en Schelling véase la informativa nota de la p. 191). Todo aquello que suele enorgullecer a los individuos procede de esta manera de una maldición metafísica y es habitual confundir el conflicto de fuerzas sin conciencia de la antehistoria [Vorgeschichte] —el Urzeit - con las dislocaciones que trae consigo la historia propiamente dicha. "[E]l fundamento inicial de la naturaleza actuaba solo", declara Schelling ${ }^{16}$, actuaba-para-sí. La ambivalencia intrínseca a las acciones históricas encuentra en Napoleón el ejemplo más actual, en un tiempo de la intensidad bélica como el contemporáneo a la redacción del Freiheitsschrift. Quien liberta se muestra al mismo tiempo como un déspota. Es lo uno porque también es lo otro, porque sus elecciones están determinadas en todo momento por un fundamento más poderoso que la razón o los ideales de la libertad. La conciencia requiere del mal para comprenderse a sí misma y, por tanto, para localizar siquiera al fundamento

\footnotetext{
${ }^{14} \mathrm{SW} \mathrm{I} / 7$, p. 399.

${ }^{15} \mathrm{SW} \mathrm{I/7,p.} 461$.

${ }^{16} \mathrm{SW} \mathrm{I} / 7$, p. 378.
} 
desde y contra el cual se yergue impulsada por las ansias de ser ella misma, por la pura potencia de ser, ciega pero persistente. Como en Hume, pero sobre todo como en Freud, la conciencia no es hija de la razón, sino que la razón es el producto engendrado por una repetición sin sentido, más allá de la inclinación a configurar algo distinto de la unidad imponente de la naturaleza coronada por la divinidad. Con ello, la retórica de la escisión del sí mismo hace escuchar sus derechos en la constitución de la dialéctica de la ambivalencia reconocible en Schelling, que hace de la perversión [Verkehrtheit] la matriz de la decisión (p. 215), a la que sucede un orden corrupto, dibujando un escenario en el que se dejan escuchar potentes ecos kantianos. Frente a la imagen luterana del sujeto como un ente sepultado por el dominio del principio bueno o del principio malo, que se disputan su poder alternante sobre él, Schelling entiende que el ser humano "deja-actuar-en-si [In-sich-handeln-lassen] al principio bueno o malo" (p. 224), esto es, les abre el acceso a su fuero interno y los hace suyos en virtud de una tendencia espontánea, no subsumida por fuerzas externas.

El ritmo de la existencia humana va de consuno con el inicio del ritmo histórico desde el momento que la voluntad del ser humano rompe con el orden y modo divinos, poniendo fin al equilibrio entre los principios por mor de la atención que dirige a lo no-ente [Nichtseiendes] a fuer de querer serlo todo ${ }^{17}$. A partir de ese momento todos los vínculos serán aparentes e insuficientes, patológicos si se los compara con la equilibrada vida del todo antes del parto de la historia, cuya fuerza estructural es precisamente el mal (p. 228). Quedando atrapada en el deseo de ser otro, de liberarse del Ebenbild de Dios, la subjetividad inaugura "[u]n movimiento estéril frente al fértil movimiento de autoengendramiento de Dios" (p. 231), esto es, el sujeto nace de una mala apuesta, que toma como interlocutor al fundamento, pero el fracaso no deja de estar acompañado en todo momento del melancólico sentimiento de "haber sido todas las cosas, concretamente en y con Dios" ${ }^{18}$, un estado al que aspira a retornar de la mano de una egocéntrica reflexión que intenta retener in extremis la luz vertida en el cántaro que es su cuerpo. Sin intervención efectiva del ser humano o, si se prefiere, de sus imágenes y deseos tentadores y seductores, no habría excitación al mal ni inversión de la divinidad, a pesar de que "[1]a historia [sea] una epopeya poetizada por el espíritu de Dios" ${ }^{19}$. El fundamento no quiere el mal ni desea ningún cambio, sino que hace sentir a otro, cuya acción suscita, pues "el mal como tal necesita de un acto propio para su irrupción" (p. 271). Y ese acto es el de la particularización y encerramiento del sujeto en su propiedad, esto es, la renuncia al carácter difusivo de la luz del espíritu. La imagen, primer objeto del querer, una imagen deseada y aún no presente de sí mismo y del mundo modifica radicalmente el mapa de relaciones entre el ser humano y la divinidad, sumiendo a la voluntad humana en los abismos de la

\footnotetext{
${ }^{17} \mathrm{SW} \mathrm{I} / 7, \mathrm{pp} .390-391$.

${ }^{18} \mathrm{SW} \mathrm{I} / 7$, p. 390.

${ }^{19} \mathrm{SW} \mathrm{I} / 6$, p. 57.
} 
desviación y final inversión. No es, pues, la razón el origen de la historia y del mal, ni siquiera puede explicar el hecho de la propia existencia, sino un resto indigerible para ella (p. 244), "algo que fuerza a trascender esos límites"20. De la honesta captación de ese resto irreductible depende el restablecimiento de la salud en el horizonte de la conciencia, consistente en la capacidad de someter el mal, sin disolverlo, borrarlo o asumirlo (pp. 249-250). Pero dar ese paso presupone que toda existencia se entienda como producto de la implosión de un conflicto interno entre potencias, así como reconocer que la subsunción lógica es demasiado pobre para expresar el nexo entre fundamento y existencia, en el que anida "una cara oculta que ni siquiera el sujeto en el más alto grado de conciencia alcanza a vislumbrar" (p. 251). La misma transitividad de la cópula debería fijar su mirada en la relación de antecedens et consequens y contractio y expansio que rige el decurso del cosmos. La lógica no puede explicar la "teología del tiempo", por decirlo en palabras de Arturo Leyte, pues la reflexión que origina el mundo lo vincula eternamente a ese fondo refractario a los ajustes de la proposición, por especulativa que esta se quiera.

De la misma manera que Dios se encuentra a sí mismo a través de la escisión de las fuerzas que permanecían replegadas en Él, el sujeto toma conciencia de sí al consumarse el proceso histórico, elevarse sobre su propia curvatura sobre sí y observar la insistente retracción de su fondo (p. 257). De hecho, cuando el mal se ha extendido universalmente y la autonomía alcanzada por todos los seres los mantiene alejados irremediablemente del centro, es el momento de elegir la salvación, como la mejor y preferible acción resultante del marco impuesto por la decisión originaria. Sin duda, podría sospecharse de la ausencia de afuera del principio divino en el sistema de Schelling, pero esta tesis debe verse acompañada de la exigencia de intervención de la voluntad humana para el advenimiento de la existencia. La misma necesidad de relevación de la divinidad, el proceso que manifieste lo-que-él-es, requiere de la irrupción del mal. Luego el mal es necesario, mejor dicho, "el bien es el mal" "21, "son lo mismo visto simplemente desde distintos lados" ${ }^{22}$, pues por de pronto sin el segundo no habría despliegue alguno ni devenir de la divinidad encarnado en la figura del acontecer histórico. En segundo lugar, el mal, simulacro y alteración de lo real perteneciente al reino lunar de lo no-ente, inicia el denuedo del bien por someter y domeñar la perversión de los principios, introduciendo en el mundo una "inversión de la inversión" (p. 265) deudora de la lógica de la oposición real reivindicada por Kant en el campo de batalla metafísico. El ser humano mantiene una deuda con el mal, toda vez que éste precipita la formación de su personalidad, esto es, de su causalidad en lo real con vistas a la efectiva realización del bien. Y este evidencia un rostro fáustico cuando reivindica

\footnotetext{
${ }^{20} \mathrm{SW} \mathrm{I} / 10, \mathrm{pp} .143-144$.

${ }^{21} \mathrm{SW} \mathrm{I} / 7$, p. 341.

${ }^{22} \mathrm{SW} \mathrm{I} / 7$, p. 400.
} 
su no estar dado, sino su hechura de conquista efectiva y de superación de un padecimiento precedente.

El mal límpido y puro [lauteres Böse] —o, "a su manera", algo puro-, decantado finalmente en el decurso de la historia como lo que no es el bien, pero solo gracias a su íntima conexión con el bien, amenazará en todo momento con romper el orden contingente de la conciencia en tanto que máxima potencialidad, aunque está en la mano del ser humano el mantenerlo sometido - el convertirlo en efectivo hypokeímenon-, esto es, el no cejar en el esfuerzo de superación de lo otro de sí. Y en ese sometimiento se cifra la autonomía del sujeto, su más preciada posesión y la más profunda revelación de lo divino que contiene el mundo, de la misma manera que el recuerdo indeleble de la no asimilación racional de este elemento constitutivo del sistema. El lector no puede sino agradecer a la profesora Carrasco-Conde la oportunidad de acceder al núcleo auténtico del pensamiento de Schelling siguiendo los pasos de esta odisea de la conciencia a partir de su alejamiento del fundamento originario y voluntaria caída hasta alcanzar la Ítaca de una salud entendida como percepción clara y distinta de las patologías oriundas de la propia mismidad. Todo ello acompañado de una selección sumamente provechosa de observaciones de Schelling y de un conjunto de notas explicativas ajustado a los fines del ensayo, que sostienen y acompañan con buen ritmo la exposición de los argumentos, contribuyendo a despertar la conciencia, la de todos, del sueño de una teleología que condena toda fricción a la contingencia y a disolver asimismo la creencia en la exterioridad del obstáculo. La odisea de la conciencia pasa a reconocerse así como la genealogía de una herida a la que la especie humana puede sobreponerse, pero nunca cerrarla de una vez para siempre. 